\title{
Ecological succession among iron-oxidizing bacteria
}

\author{
Emily J Fleming ${ }^{1}$, Ivona Cetinić ${ }^{2}$, Clara S $\mathrm{Chan}^{3}$, D Whitney King ${ }^{4}$ and David Emerson ${ }^{1}$ \\ ${ }^{1}$ Bigelow Laboratory for Ocean Sciences, East Boothbay, ME, USA; ${ }^{2}$ University of Maine, Darling Marine \\ Center, Walpole, ME, USA; ${ }^{3}$ Department of Geological Sciences, University of Delaware, Newark, DE, \\ USA and ${ }^{4}$ Department of Chemistry, Colby College, Waterville, ME, USA
}

\begin{abstract}
Despite over 125 years of study, the factors that dictate species dominance in neutrophilic iron-oxidizing bacterial $(\mathrm{FeOB})$ communities remain unknown. In a freshwater wetland, we documented a clear ecological succession coupled with niche separation between the helical stalk-forming Gallionellales (for example, Gallionella ferruginea) and tubular sheath-forming Leptothrix ochracea. Changes in the iron-seep community were documented using microscopy and cultivation-independent methods. Quantification of Fe-oxyhydroxide morphotypes by light microscopy was coupled with species-specific fluorescent in situ hybridization (FISH) probes using a protocol that minimized background fluorescence caused by the Fe-oxyhydroxides. Together with scanning electron microscopy, these techniques all indicated that Gallionellales dominated during early spring, with $L$. ochracea becoming more abundant for the remainder of the year. Analysis of tagged pyrosequencing reads of the small subunit ribosomal RNA gene (SSU rRNA) collected during seasonal progression supported a clear Gallionellales to $L$. ochracea transition, and community structure grouped according to observed dominant FeOB forms. Axis of redundancy analysis of physicochemical parameters collected from iron mats during the season, plotted with FeOB abundance, corroborated several field and microscopy-based observations and uncovered several unanticipated relationships. On the basis of these relationships, we conclude that the ecological niche of the stalk-forming Gallionellales is in waters with low organic carbon and steep redoxclines, and the sheath-forming $L$. ochracea is abundant in waters that contain high concentrations of complex organic carbon, high $\mathrm{Fe}$ and $\mathrm{Mn}$ content and gentle redoxclines. Finally, these findings identify a largely unexplored relationship between $\mathrm{FeOB}$ and organic carbon.
\end{abstract}

The ISME Journal (2014) 8, 804-815; doi:10.1038/ismej.2013.197; published online 14 November 2013 Subject Category: Microbial population and community ecology

Keywords: FeOB; Gallionella; Leptothrix ochracea; neutrophilic; freshwater iron mats; Sideroxydans; seasonal dynamics

\section{Introduction}

Bacterial succession has been a difficult process to study in the field largely because of the lack of easily identifiable, distinct species markers. Iron-oxidizing bacteria $(\mathrm{FeOB})$ are unusual in that they generate large quantities of morphologically distinct, biogenically formed iron oxyhydroxide structures, or morphotypes, that can be easily recognized by light microscopy (van Veen et al., 1978; Winogradsky, 1888; Emerson et al., 2010; Chan et al., 2011). Different morphotypes have been linked phylogenetically, through cultivation-independent studies, to the order Gallionellales (stalk and particulates) or the genus Leptothrix (sheaths; including the

Correspondence: EJ Fleming, Bigelow Laboratory for Ocean Sciences, PO Box 380, East Boothbay, ME 04544, USA.

E-mail: efleming@bigelow.org

Received 21 June 2013; revised 2 September 2013; accepted 22 September 2013; published online 14 November 2013 dominant sheath-forming FeOB, $L$. ochracea) (Chan et al., 2011; Fleming et al., 2011). In slow-moving waters, these $\mathrm{FeOB}$ produce loosely flocculent oxyhydroxide layers that can be centimeters thick, whereas in faster-flowing waters the oxyhydroxides form thinner, denser layers of only a few millimeters. These microbial iron mats are hotspots of microbial activity that entrain nutrients and trace metals. From a practical standpoint, the activity of FeOB leads to biofouling and deterioration of wells, pipes and water distribution systems (Katsoyiannis and Zouboulis, 2006; Emerson et al., 2010; Li et al., 2010); thus, there is interest in determining the cause of their proliferation.

Climatic and environmental factors contribute to microbial community dynamics and variance (Kent et al., 2007). FeOB communities are typically constrained to redoxcline habitats with high concentrations (10s-100s of $\mu \mathrm{M})$ of $\mathrm{Fe}(\mathrm{II})$. The physical or chemical niche preference of the two most apparent FeOB, however, has been 
difficult to determine. It has been challenging to find locations where one $\mathrm{FeOB}$ morphotype (that is, sheaths or stalks) and the small subunit ribosomal RNA (SSU rRNA) gene sequences clearly dominate over the other (for example, Haaijer et al., 2008; Duckworth et al., 2009; Bruun et al., 2010; Gault et al., 2012). One explanation for this may be that localized gradients within an ecosystem result in microenvironments that allow for different FeOB to coexist. An example of this was seen in a highly structured iron mat in Denmark in which L. ochracea dominated most of the mat, but there were still small areas where the stalks of Gallionella were prevalent, even within a few centimeters of L. ochracea-dominated regions (Emerson and Revsbech, 1994). The first systematic study that shed light on the population dynamics of FeOB in multiple iron mat communities was performed in Wisconsin and Minnesota by Harder (1919). He observed that some Fe-rich springs and Fe-rich accretions in underground mine shafts were dominated by stalk formers, whereas other wetlandassociated sites were dominated by $L$. ochracea-like sheaths. Harder hypothesized that the heterogenous distribution of different $\mathrm{FeOB}$ forms was due to differences in the chemical composition of waters feeding the iron mats; however, verification of this hypothesis and specification of key parameters have been elusive until now.

On observing samples collected from a local iron mat community, initially by light microscopy, we identified a temporal variation in the FeOB populations of a freshwater stream. It appeared to be dominated by Gallionella-like stalks in the spring and by Leptothrix-like sheaths in the summer. On the basis of these preliminary observations, we hypothesized that there is a distinct successional transition between dominant $\mathrm{FeOB}$ morphotypes, and that the chemical composition of the waters is likely responsible for this pattern. Defining these temporal dynamics allowed us to better understand the ecological niches occupied by different FeOB communities and predict which resources favor different populations of $\mathrm{FeOB}$ that are associated with different morphotypes.

\section{Materials and methods}

Site and sample collection

Freshwater iron mats associated with a small firstorder stream in Boothbay Harbor, ME, adjacent to Lakeside Drive (LD; Figure 1; $43^{\circ} 51.6999^{\prime} \mathrm{N}$, $69^{\circ} 38.9299^{\prime} \mathrm{W}$ ), were observed during five seasons (2008-2012) and regularly sampled during the 2009 and 2010 seasons. The general site characteristics were described in Fleming et al. (2011) and additional details are provided in Supplementary File 1. Depending on the morphological structures present in the mats, the mats and the water above the mat were sampled at either weekly or monthly intervals

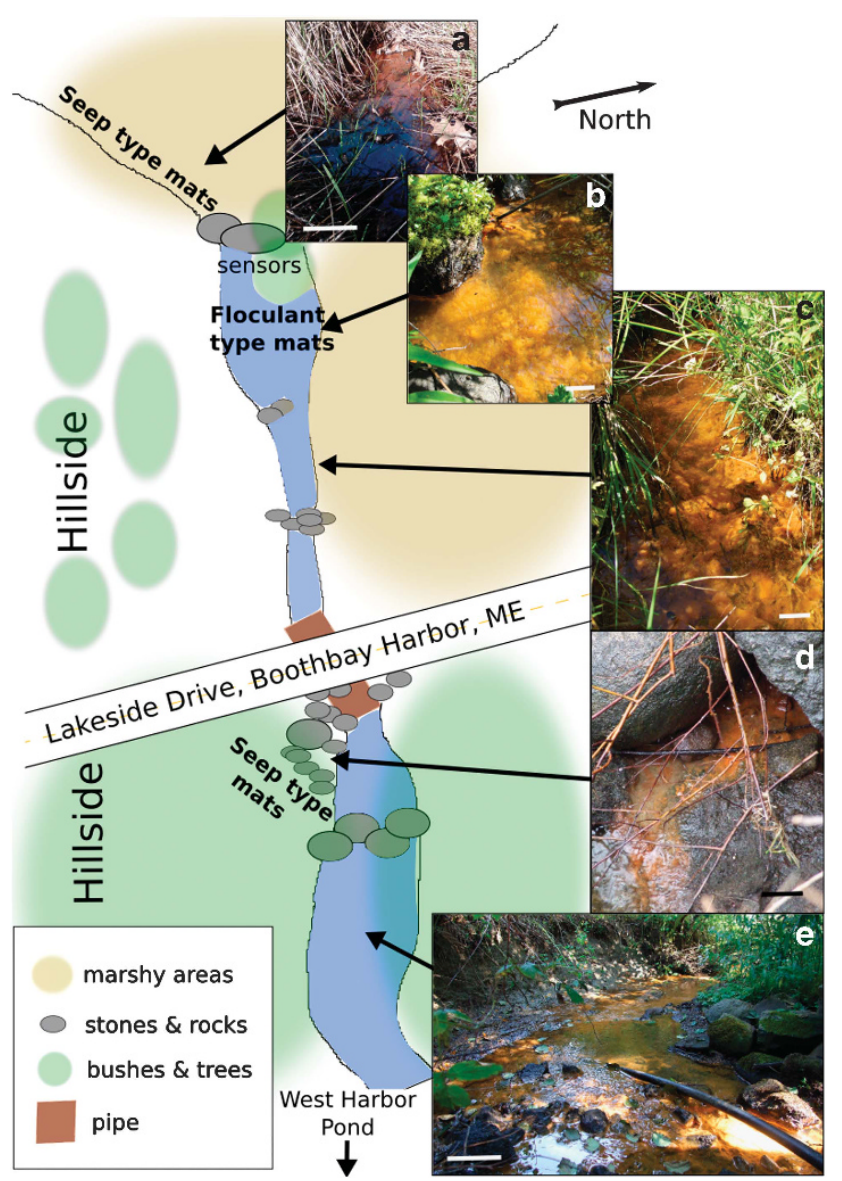

Figure 1. Lakeside Drive study site in the town of Boothbay Harbor, Maine. The length of stream and marshy areas is approximately $75 \mathrm{~m}$. The study site includes several mat types: seep type mats $(\mathbf{a}, \mathbf{d})$ in the early spring and flocculent type mats $(\mathbf{b}, \mathbf{c}, \mathbf{e})$ in the late spring/early summer. Scale bars are $10 \mathrm{~cm}$ (images a-d) and $100 \mathrm{~cm}$ (image e). Images (a-d) were taken facing upstream, and image (e) was taken facing downstream.

for analysis of biological, chemical and physical parameters.

Mats were sampled using a Pasteur pipette to collect only the top $0.5 \mathrm{~cm}$ that composed the outer layer of either loosely flocculent or condensed mats. This outer section is the most active accreting region, and has been shown to contain a high proportion of FeOB (Emerson and Weiss, 2004; Fleming et al., 2011).

Microscopy and structural analysis of mat community For structural analysis by light microscopy or scanning electron microscopy (SEM), fresh samples were preserved by adding glutaraldehyde $2.0 \%$ final concentration; Electron Microscopy Sciences, Hatfield, PA, USA) and stored at $4{ }^{\circ} \mathrm{C}$ until analysis. The percentage of biogenic Fe-oxyhydroxide structure (stalk, sheath or particulate) in each sample was determined by first spreading $10 \mu \mathrm{l}$ of sample on an agarose-coated slide (Electron Microscopy Sciences) and then capturing at least 
10 fields of view with 15 structures (on average) present in each microscopic field. Microscopic analysis was performed using an Olympus BX60 microscope equipped with a QICAM FAST CCD camera and QCapture Pro software (QImaging, Surrey, BC, Canada) as described in Emerson and Moyer (2002). Images were then imported into Image (Rasband, 2004), and each structure was outlined using a Wacom Intuos4 Pen tablet (Vancouver, WA, USA). The surface area of each outlined structure was calculated using the area analysis tool in ImageJ, and counted toward the total percentage area for each structure type. In the fall after the summer transition, sheaths were predominant, and the sheath and stalk ratio was evaluated qualitatively by microscopy.

\section{SEM and EDX analysis}

Samples for SEM were dehydrated in an ethanol series and critical point dried (Autosamdri-815B CPD), mounted on an aluminum stub and coated with carbon (Denton Bench Top Turbo III coater). Imaging was performed at the Delaware Biotechnology Institute Bioimaging Facility using a Hitachi S-4700 field emission SEM with an accelerating voltage of $3.0 \mathrm{kV}$. Energy dispersive X-ray (EDX) spectroscopy was performed at $15 \mathrm{kV}$ using an Oxford Inca X-act detector.

\section{Fluorescent In Situ Hybridization}

For fluorescent in situ hybridization (FISH), freshly collected mat was preserved in $4 \%$ paraformaldehyde for $1.5 \mathrm{~h}$, washed three times with $1 \times$ phosphate-buffered saline, resuspended in 1:1 phosphate-buffered saline/ethanol solution and stored at $-20^{\circ} \mathrm{C}$. A known sample volume (between 3 and $20 \mu \mathrm{l})$ was spread into a ClearCell slide (Thermoscientific, Cell Line Brand, Portsmouth, NH, USA) and air-dried at room temperature.

Several potential Gallionellales-specific probe sequences were designed using ARB software (Ludwig et al., 2004) in combination with the Silva 102 database (Pruesse et al., 2007). Probes were designed to incorporate members of the Gallionellales order including Gallionella and Sideroxydans. Probe Gal221 (5'-CTTTCGGAGTGGCCGAT-3'; (Eurofins MWG Operon, Huntsville, Alabama, USA)) was ranked highly by the probe match tool in ARB and further tested for its ability to hybridize to cells.

Cy3-labeled candidate probe Gal221 was then evaluated at various stringencies by its ability to hybridize with Sideroxydans lithitrophicus ES-1 and iron mats enriched in Gallionella stalks. Probe stringency was modulated by formamide concentration using the standard FISH protocols in combination with several of the blocking reagents used for CARD (Catalyzed Reporter Deposition)FISH protocols (Fuchs et al., 2007; Fleming et al., 2011). Probe stringency at different formamide concentrations was determined by measuring relative fluorescence using an epifluoresence microscope as described in Fleming et al. (2011). The optimum stringency for Gal221 probe was 35\% formamide.

For cell counts, the Gal221 probe, as well as the Lepto175 probe (for L. ochracea; ATCCACAGATCA CATGCG; also (Eurofins MWG Operon, Huntsville, Alabama) (Fleming et al., 2011), was used. Each sample analyzed by FISH was probed in triplicate, and at least 10 fields were counted per well. In addition, total microbial cells were counted in triplicate by drying cells on ClearCells slides, staining them with Syto13 (Invitrogen-Life technologies, Grand Island, NY, USA) and counting all the cells ( $\geqslant 10$ fields). Epifluoresence imaging and visualization was performed using an Olympus BX60 microscope.

\section{Community sequencing and data processing}

To understand the microbial population structure of the iron mat community, eight temporally spaced samples from LD were analyzed using tagged pyrosequencing. Total community DNA was extracted from $\geqslant 15 \mathrm{ml}$ of freshly collected (not frozen) mat sample using MoBio Power Water DNA extraction (as per the manufacturer's recommendations; Carlsbad, CA, USA) and stored at $-20^{\circ} \mathrm{C}$. Extracted DNA samples (at DNA concentrations of 3.4-100 ng $\mathrm{Ll}^{-1}$ ) were sent for tagged pyrosequencing of the V4-V6 region to the Research and Testing Laboratory (Lubbock, TX, USA), and processed as described in Dowd et al. (2008). Samples were sequenced on a Roche 454 FLX system with Titanium Chemistry (Roche, Nutley, NJ, USA) using tags, barcodes and primers listed in Supplementary Table 1. Samples were processed in Mothur 1.28.0 according to the Schloss Standard Operating Protocol (Schloss et al., 2011; http://www.mothur.org/ wiki/Schloss_SOP, first accessed in March 2012). After a stringent processing protocol that involved trimming, quality checking, removing chimeras and screening using Mothur (Table 1), sequences were aligned using the Silva database (Pruesse et al., 2007) and classified using a modified version of the NCBI classification hierarchy that included several known FeOB as described in McBeth et al. (2013).

All sequences from the tagged pyrosequencing libraries were submitted to the NCBI short-read archive under accession number SRP008006.

\section{Analysis of physicochemical constituents}

Physicochemical parameters at the LD site were determined both in situ and by laboratory analysis of collected samples. Continuous in situ water temperature was measured using three Hobo Pendant temperature/light sensors (Onset Computers, UA002-64, Bourne, MA, USA), and air temperature was obtained from NOAA data for the nearby Wiscasset 
Table 1 Statistical summary of tagged pyrosequencing reads for samples used in this study

\begin{tabular}{|c|c|c|c|c|c|c|c|c|}
\hline \multirow{2}{*}{$\begin{array}{l}\text { Date of } \\
\text { sample } \\
\text { collection }\end{array}$} & \multirow{2}{*}{$\begin{array}{c}\% \text { of high } \\
\text { quality } \\
\text { sequences } \\
\text { post-processing }\end{array}$} & \multirow{2}{*}{$\begin{array}{c}\text { Number } \\
\text { of sequences } \\
\text { post- } \\
\text { processing }\end{array}$} & \multirow{2}{*}{$\begin{array}{c}\text { Estimated } \\
\% \text { coverage } \\
(0.03)^{\mathrm{a}}\end{array}$} & \multirow{2}{*}{$\begin{array}{l}\text { Number of } \\
\text { operational } \\
\text { taxonomic } \\
\text { units }(0.03)^{\mathrm{a}}\end{array}$} & \multirow{2}{*}{$\begin{array}{l}\text { Berger } \\
\text { Parker } \\
\text { index } \\
(0.01)^{\mathrm{a}}\end{array}$} & \multirow{2}{*}{$\begin{array}{l}\text { Inverse } \\
\text { simpson } \\
\text { index } \\
(0.03)^{\mathrm{a}}\end{array}$} & \multicolumn{2}{|c|}{$\begin{array}{c}\% \text { sequences } \\
\text { from genus or order }\end{array}$} \\
\hline & & & & & & & $\begin{array}{l}\text { Leptothrix } \\
\text { spp. }\end{array}$ & Gallionellales \\
\hline $\mathrm{LD} 4 / 22$ & 15.1 & 922 & 96.10 & 87 & 17.35 & 14 & 0.5 & 4.8 \\
\hline LD 5/14 & 10.5 & 471 & 47.13 & 302 & 1.91 & 163 & 0.0 & 1.1 \\
\hline LD 5/21 & 46.2 & 1590 & 70.82 & 684 & 2.95 & 156 & 0.2 & 0.9 \\
\hline LD 5/23 & 18.4 & 976 & 66.91 & 417 & 11.78 & 32 & 13.1 & 1.4 \\
\hline LD 6/01 & 13.6 & 811 & 80.15 & 261 & 7.64 & 56 & 3.8 & 0.4 \\
\hline LD 6/04 & 38.5 & 2340 & 79.87 & 697 & 7.31 & 37 & 7.7 & 2.9 \\
\hline LD 7/02 & 17.6 & 1115 & 69.51 & 446 & 9.24 & 41 & 4.2 & 1.8 \\
\hline LD 9/30 & 14.9 & 1104 & 84.42 & 246 & 21.47 & 11 & 22.7 & 1.8 \\
\hline
\end{tabular}

Abbreviation: LD, Lakeside Drive.

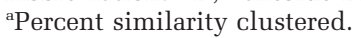

Airport, ME (http://www.ncdc.noaa.gov/cdo-web/). The stream $\mathrm{pH}$ was measured in situ with either a Check-Mite pH-20 (Corning, Tewksbury, MA, USA) or color-pHast EMD pH indicator strips (EMD, Gibbstown, NJ, USA). Oxygen profiles were determined in the field in April and October with a Clarktype electrode and an $\mathrm{ISO}_{2}$-dissolved oxygen meter (World Precision Instruments, Sarasota, FL, USA).

$\mathrm{Fe}(\mathrm{II})$ concentrations were determined by ferrozine assay, in which water samples were filtered through a $0.2 \mu \mathrm{m}$ syringe filter (Millipore, Billerica, MA, USA), added to ferrozine (Stookey, 1970), buffered in acetic acid and reduced with hydroxylamine (total iron only). The sample absorbance (in sextuplicates) was measured on a Thermo Scientific Multiskan MCC plate reader (Rockford, IL, USA) at $562 \mathrm{~nm}$ and converted to iron concentrations based on a standard curve of known Fe(II) concentrations.

Water samples for inorganic nutrients analysis were collected with a sterile $35 \mathrm{ml}$ syringe and filtered through a cellulose acetate $0.2-\mu \mathrm{m}$ filter (VWR, Radnor, PA, USA). Trace metal clean nitric acid (trace metal grade, Sigma; $80 \mathrm{~mm}$ final concentration) was added to each sample and stored at $4{ }^{\circ} \mathrm{C}$ until analysis by inductively coupled plasma atomic emission spectroscopy (ICP-AES) (Spectro, Arcos, Kleve, Germany). The instrument was calibrated using multi-element standards in the range of 0-10000 p.p.b. with detection limits of less than 5 p.p.b. for most elements. All samples were run in triplicate (Supplementary File 2).

Water samples for dissolved organic carbon (DOC) and spectral absorption coefficient of the dissolved matter $\left(a_{\text {diss }}(\lambda)\right)$ were filtered in the field through a $0.45 \mu \mathrm{m}$ nominal pore size Whatman GF/F filter (Whatman, Piscataway, NJ, USA) to remove particulates. The filtrate was stored in RBS 35 Detergent Concentrate (Thermo Scientific, Rockford, IL, USA) washed glass vials, at either $-80^{\circ} \mathrm{C}$ or $-20^{\circ} \mathrm{C}$, until analysis. The DOC samples were analyzed at Horn
Point Laboratory, University of Maryland, on Shimadzu TOC-5000A following the method described in Sugimura and Suzuki (1988). The filtered samples collected for determination of $a_{\text {diss }}(\lambda)$ were acclimated to room temperature $\left(\sim 20^{\circ} \mathrm{C}\right)$, transferred to 1-cm light path quartz cuvettes and analyzed on a Varian Cary 50 Bio UV-visible spectrophotometer (Santa Clara, CA, USA) at 1-nm resolution with a wavelength range of $200-800 \mathrm{~nm}$. Each sample was scanned three times. The baseline correction for each spectral scan was carried out using Milli-Q water alone. Instrument stability was monitored throughout the analysis by running MilliQ water blanks. All water samples were analyzed within 5 months of collection.

Two $a_{\text {diss }}$ slope ratios (275-295-nm slope: 350-400-nm slope) can be used to relate changes in dissolved organic matter to DOC molecular weight (MW) (Helms et al., 2008). The increase in these two slope ratios indicates a decrease in MW for freshwater, estuarine and marine samples. Following the approach outlined by Helms et al., (2008), a linear function was fitted on the log-transformed data from two wavelength ranges: $275-295 \mathrm{~nm}$ and $350-400 \mathrm{~nm}$. For convenience, here we have used inverted (Helms et al., 2008) slope ratio, slope $(350-400 \mathrm{~nm}) /$ slope $(275-295 \mathrm{~nm})$, wherein an increase in spectral slope indicates an increase in MW and an increase in functional aromaticity.

\section{Statistical analysis}

Redundancy analysis (RDA), a multivariate canonical ordination analysis, was used to define the relationships between FeOB species abundances (dependent variables) and environmental parameters (explanatory variables) that were not easily apparent in simple pair-wise analyses. This multivariate statistical analysis facilitates visualization of observed trends by coupling taxonomical and environmental data sets in a single two-dimensional 
biplot (Ramette, 2007), providing a more robust interpretation of the data. Prior to the analysis, environmental data were standardized by subtracting the mean and dividing by the standard deviation. The FISH-based cell counts were logarithmically transformed. In the resulting distance biplot, species locations and distances between them (based on the respective ordination scores) indicated their similarity to one another. Environmental parameters are depicted as vectors: the vector length indicates the importance to the ordination (and its effect on species variation); the vector direction depicts the gradient of the respective environmental variable in the ordination space (starting from the center out); both length and direction describe its correlation with the axes. The species (dependent variables) and the environmental vector proximity in the biplot (ordination space) indicate the correlation strength. The environmental variables that had a canonical coefficient lower than 0.05 were omitted from the biplot.

Principal Coordinates Analysis (PCoA) was used to assess the similarity in community structure along the sampling period. Ordination was generated in R (R Core Team (2012), http://www.r-project.org) using a Yue and Clayton-based distance matrix calculated in Mothur from the tagged pyrosequencing data set where relative abundance of operational taxonomic units (OTUs) was defined at $3 \%$ OTU definition level.

\section{Results}

Repeated seasonal development of $L D$ iron mats Iron mats were present at LD every spring and summer throughout our 5-year study period, making them an ideal system for investigating seasonal changes in FeOB mat populations and communities. Following the spring thaw in Maine (between midApril and early May), LD iron mats first developed in marshy areas at the base of small hummocks and eroded hillsides (Figures 1a and d). The mats were thick (1-3 cm), consolidated, dark in color and overlaid with approximately $1 \mathrm{~cm}$ of stagnant or slowly flowing $\left(<1 \mathrm{~cm} \mathrm{~s}^{-1}\right)$ water. By late May and early June, the mats became established in the main stream channels (Figures 1b, c and e). These mats were lighter in color and more flocculent, filling the entire streambed to a depth of $30 \mathrm{~cm}$ during 'blooms.'

Systematic microscopic examination of mat samples collected from the marshy areas (Figure 1) in the April of both 2009 and 2010 revealed an abundance of stalk and particulate structures (Figure 2) (indicative of the Gallionellales) and an absence of sheaths. As the mats became established in the main stream channel during May and June, the sheath structures began to dominate (indicative of Leptothrix spp.) until stalks or particulates were rare or absent (Figure 2). During the remainder of the
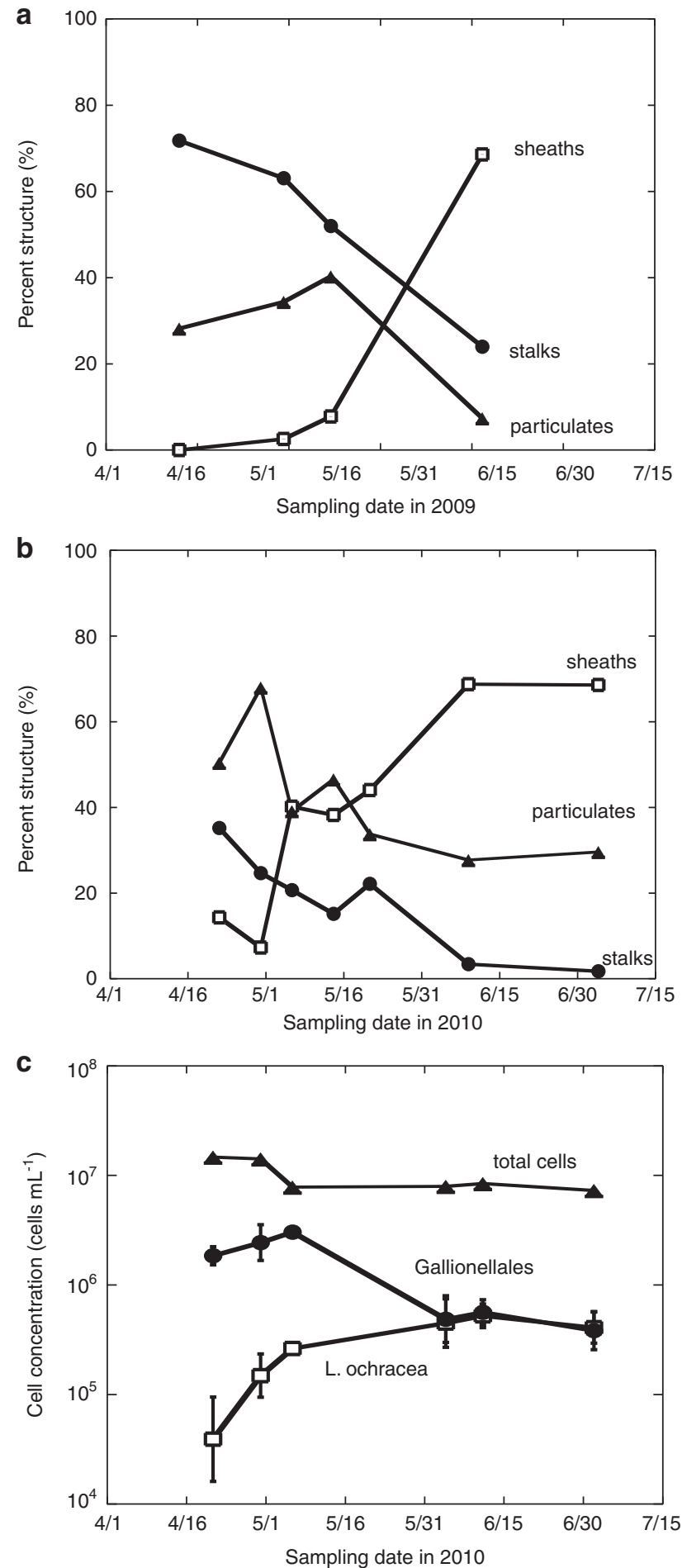

Figure 2. Percent sample containing either sheaths (open squares), stalks (filled circles), or disorganized particulate (triangles) iron-oxyhydroxides in LD during 2009 (a) and 2010 (b) and concentration of total cells (triangles; cells staining with Syto13), Gallionellales cells (filled circles; using FISH probe Gal221) and L. ochracea cells (open squares; using Lepto175 probe) (c). Error bars represent triplicate samples.

summer and through the fall, the sheath structures prevailed until the stream began to freeze (usually mid-November). 
Morphotype and molecular shifts of $\mathrm{FeOB}$ in LD iron mats

Water temperatures in LD closely tracked the changes in air temperature, indicating that the stream's primary water source was meteoric rather than a spring-fed system (Supplementary Figure 1). In 2010, relatively few precipitation events occurred in early spring. Intense precipitation events in the late spring/early summer resulted in stream flows $>10 \mathrm{~cm} \mathrm{~s}^{-1}$ and completely washed out the flocculent, Leptothrix-dominated mats, and in some cases scoured the streambed clean. Following the precipitation events, stream flows and levels decreased within a few days, resulting in a bloom of FeOB and production of new iron mats that were similar in the abundance and type of Fe(III) oxyhydroxide structures prior to the flushing event.

SEM analysis of mats collected in April and June of 2010 not only confirmed light microscopy observations but also revealed the detailed ultrastructure of iron-oxyhydroxide forms (Figure 3). In April, the mats contained all three dominant structural types with stalks being the most abundant morphotype. By June, sheaths dominated; the particulate oxyhydroxides were less dense and formed as clumps on the sheaths. Energy dispersive $\mathrm{X}$-ray analysis confirmed that all structures were composed of iron-oxyhydroxides.

FISH analysis revealed a shift in the prevalent FeOB species at LD (Figure 2). In April and early May of 2010, Gallionellales-related cells dominated the mats, whereas L. ochracea cell numbers were not detected. L. ochracea cell numbers increased from late May into June and persisted until the end of summer. Lepto175-labeled cells were in chains of 10-50 cells inside a long sheath that was otherwise empty, consistent with the morphology of L. ochracea. Some Gal221-labeled cells were bean-shaped and attached to the end of helical stalks, typical of $G$. ferruginea, whereas other Gal221-labeled cells were more rod-shaped, consistent with the morphology of Sideroxydans spp., associated with particulate Fe(III)-oxyhydroxides (Weiss et al., 2007). It is important to note that several pure cultures of Gallionellales-related FeOB do not form stalks or identifiable Fe(III)-oxyhydroxide structures (Emerson and Moyer, 1997; Weiss et al., 2007; Lüdecke et al., 2010); thus, the absence of stalks does not necessarily reflect the absence of this FeOB family. This may explain why Gallionellales FISH counts decreased with stalk disappearance but remained present throughout the remainder of the sampling season (Figure 2).

To understand the temporal changes in the microbial community structure of the LD iron mats, the V4-V6 SSU rRNA gene from eight samples (April to September 2010) were pyrotagged, sequenced and compared. The number of highquality reads recovered varied greatly (471-2340; Table 1), as did the estimated coverage at the $3 \%$ similarity clustering level (47.1-96.1\%, Table 1). In general, samples collected on 14 May and 21 May were more diverse and had a more even distribution of taxa (lower Berger-Parker indices, greater Inverse Simpson index, Table 1, and greater slope in the rarefaction curves, Supplementary Figure 2). Principal component analysis of community membership produced three different clusters: the 22 April sample, the 14 May sample and the 21 May sample, and the rest of the samples taken later in the

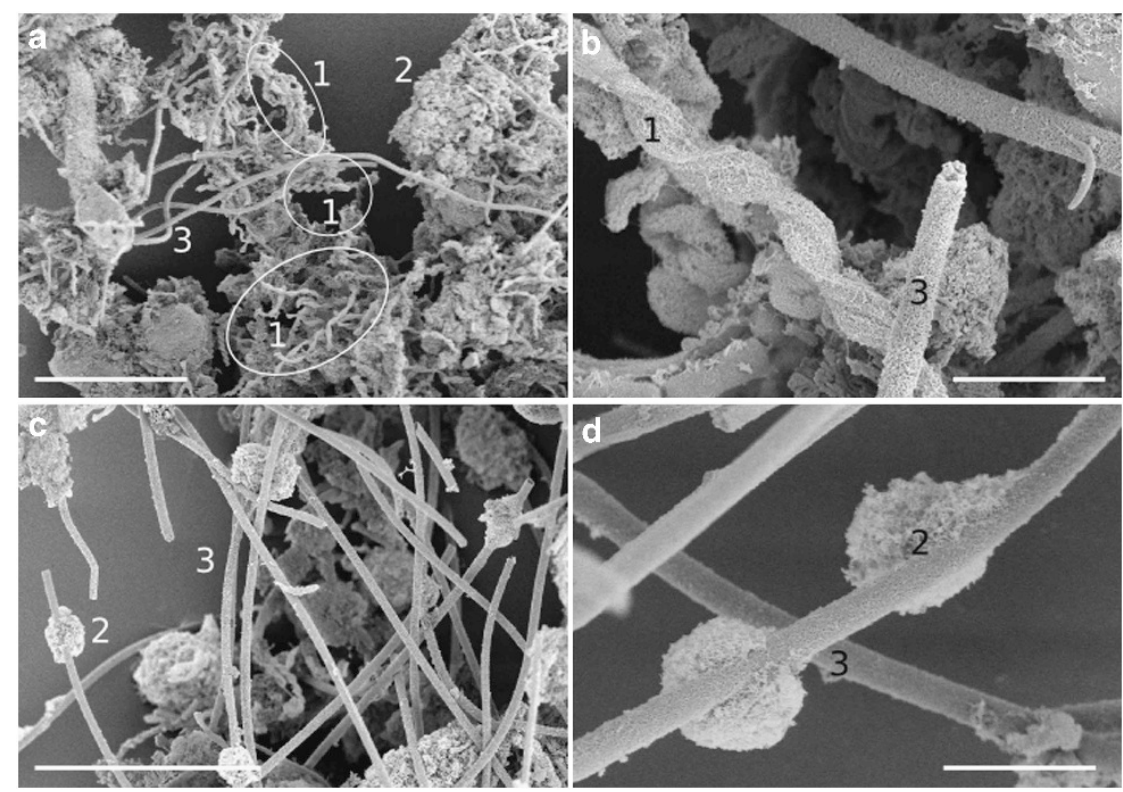

Figure 3 Scanning electron micrographs of mats collected on 22 April (a, b) and mats collected on 1 June (c, d) with various stalk morphologies (1), disorganized iron-oxyhydroxide particulates (2) and sheaths (3). Scale bars for less magnified images (a, c) are $30 \mu \mathrm{m}$ and those for magnified images are $5 \mu \mathrm{m}(\mathbf{b}, \mathbf{d})$. 
year (Supplementary Figure 5). Leptothrix spp. reads increased throughout the season, whereas the Gallionellales reads, after the initial high numbers (sample collected on 22 April), decreased and remained stable (Table 1). The composition of OTUs and total pyrotagged reads also varied over time. The highest OTU-based diversity was encountered in samples collected in mid-May. Samples collected in April or June/July were less diverse, as seen from the higher values of Berger-Parker diversity index $(>3)$. Bacteroidetes reads were most abundant in the Gallionellales-dominated sample collected on 22 April, whereas OTUs associated with various other Betaproteobacteria were abundant in the late summer samples (Supplementary Figure 3). The most abundant OTUs were classified as Flavobacterium (in samples collected on 22 April: $24.5 \%$ of total pyrotagged reads), unclassified environmental bacteria OTU (1 June: 20.5\%; 4 June: 7.0\%; 2 July: 12.6\%), Methylobacter (4 June: $20.0 \%$; 2 July: $17.8 \%$, 30 September: $12.1 \%$ ) or
Leptothrix ochracea (4 June: 7.7\%, 30 September: $22.4 \%$ ).

On the basis of these results, the iron mat community can be described as having three phases: a Gallionellales-stalk-dominated phase in April; a relatively rapid transition period in May, with greater overall taxonomic diversity in the mats; and a longer L. ochracea-sheath-dominated phase that lasted from late spring through summer/early fall, with less overall diversity compared with the other two phases.

Environmental conditions during iron-mat evolution Seasonal microbial succession was accompanied with changes in the physicochemical conditions (Table 2). The pH became more acidic with time but stabilized during the transition and Leptothrix phases. The denser Gallionellales-dominated mats had steeper oxygen gradients than the flocculent Leptothrix-rich mats, and overall oxygen

Table 2 Summary of physicochemical data collected at Lakeside Drive in 2010

\begin{tabular}{|c|c|c|c|}
\hline \multirow[t]{2}{*}{ Date range in 2010} & \multicolumn{3}{|c|}{ Dominant phase } \\
\hline & $\begin{array}{c}\text { Gallionellales } \\
4 / 3-5 / 3\end{array}$ & $\begin{array}{c}\text { Transition } \\
5 / 6-5 / 23\end{array}$ & $\begin{array}{l}\text { Leptothrix ochracea } \\
\quad 5 / 26-9 / 30\end{array}$ \\
\hline \multicolumn{4}{|l|}{ Biomarker quantification } \\
\hline$\%$ Stalks & $30.0 \pm 7.5$ & $19.4 \pm 3.7$ & $2.6 \pm 1.2$ \\
\hline$\%$ Sheaths & $10.8 \pm 5.0$ & $40.8 \pm 3.0$ & $68.7 \pm 0.1$ \\
\hline \multicolumn{4}{|l|}{ Physical parameters } \\
\hline Water temperature $\left({ }^{\circ} \mathrm{C}\right)$ & $11.6 \pm 1.4$ & $13.1 \pm 2.4$ & $15.7 \pm 1.4$ \\
\hline $\operatorname{Rain}^{\mathrm{a}}\left(\mathrm{cm} \mathrm{hr}^{-1}\right)$ & $0.12 \pm 0.18$ & $0.56 \pm 0.73$ & $1.0 \pm 0.95$ \\
\hline \multicolumn{4}{|l|}{ Gross chemical parameters } \\
\hline Change in oxygen with depth from the & {$\left[\mathrm{O}_{2}\right]=-50(\mathrm{x}) \mu \mathrm{Mcm}^{-1}$} & not determined & {$\left[\mathrm{O}_{2}\right]=-4(\mathrm{x}) \mu \mathrm{Mcm}^{-1}$} \\
\hline surface of the mat ${ }^{\mathrm{b}}$ & $+139 \mu \mathrm{M}$ & & $+39 \mu \mathrm{M}$ \\
\hline & $\mathrm{R}^{2}=0.94$ & & $\mathrm{R}^{2}=0.76$ \\
\hline $\mathrm{pH}$ & $6.1 \pm 0.5$ & $5.2 \pm 0.5$ & $5.2 \pm 0.2$ \\
\hline $\begin{array}{l}\text { Dissolved ferrous iron ( } \mu \mathrm{M} \text {; passed through } \\
\text { a filter of } 0.2 \mu \mathrm{m} \text { in size) }\end{array}$ & $7 \pm 7$ & $59 \pm 27$ & $89 \pm 70$ \\
\hline $\mathrm{DOC}\left(\mathrm{mgl}^{-1}\right)$ & $4.8 \pm 1.5$ & $7.3 \pm 0.1$ & $7.1 \pm 1.3$ \\
\hline Spectral slope ratio & $1.005 \pm 0.021$ & $1.081 \pm 0.057$ & $1.128 \pm 0.107$ \\
\hline \multicolumn{4}{|l|}{ Major conservative elemental constituents ${ }^{\mathrm{C}}$} \\
\hline $\mathrm{Na}$ & $5.26 \pm 4.13$ & $0.00 \pm 0.00$ & $1.34 \pm 1.74$ \\
\hline $\mathrm{Mg}$ & $64.0 \pm 32.7$ & $23.4 \pm 4.6$ & $57.8 \pm 41.1$ \\
\hline K & $52.4 \pm 34.1$ & $26.2 \pm 24.6$ & $23.5 \pm 20.3$ \\
\hline $\mathrm{Ca}$ & $67.2 \pm 21.5$ & $33.1 \pm 11.8$ & $53.4 \pm 22.4$ \\
\hline $\mathrm{Cl}$ & $126.9 \pm 124.1$ & $20.7 \pm 1.8$ & $30.0 \pm 9.5$ \\
\hline $\mathrm{Al}$ & $3.0 \pm 1.0$ & $1.7 \pm 0.7$ & $2.8 \pm 1.3$ \\
\hline \multicolumn{4}{|l|}{ Biologically active redox elements ${ }^{\mathrm{c}}$} \\
\hline $\mathrm{P}$ & $0.3 \pm 0.2$ & $1.0 \pm 0.9$ & $0.9 \pm 0.5$ \\
\hline$S$ & $55.9 \pm 19.3$ & $16.3 \pm 5.5$ & $24.4 \pm 14.1$ \\
\hline Mn & $1.6 \pm 1.3$ & $2.3 \pm 0.9$ & $10.1 \pm 10.9$ \\
\hline $\mathrm{Fe}$ & $5.0 \pm 4.0$ & $7.3 \pm 2.4$ & $22.8 \pm 14.4$ \\
\hline $\mathrm{Ni}$ & $0.04 \pm 0.02$ & $0.03 \pm 0.04$ & $0.009 \pm 0.01$ \\
\hline $\mathrm{Cu}$ & $0.6 \pm 0.4$ & $1.4 \pm 1.7$ & $0.2 \pm 0.3$ \\
\hline $\mathrm{Zn}$ & $0.3 \pm 0.08$ & $0.7 \pm 0.7$ & $0.02 \pm 0.1$ \\
\hline
\end{tabular}

Abbreviation: DOC, dissolved organic carbon.

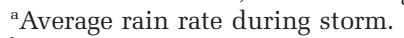

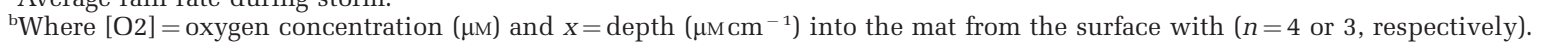

${ }^{\mathrm{c}}$ Elemental concentrations are in $\mu \mathrm{M}$. 
concentrations were significantly higher in the Leptothrix-dominated mats (Table 2, Supplementary Figure 4). The DOC concentrations and the spectral slopes ratio increased with time (Supplementary Figure 1), although the averages during each dominant $\mathrm{FeOB}$ phase did not differ significantly (Table 2). Similarly, trends in elemental concentration could not easily be assigned to a particular phase of the three-phase model, suggesting a complex system where elemental concentrations might lag or precede changes observed in microbial species (Table 2). Some elements did cooccur with one another, including $\mathrm{Fe}$ and $\mathrm{Mn}$ $\left(r^{2}=0.44, P=0.005\right)$ and clay elements $\mathrm{Al}$ and $\mathrm{Ca}$ $\left(r^{2}=0.34, P=0.012\right)$ (Supplementary Information 2).

To gain a better understanding of the dynamics and underlying mechanisms controlling the temporal evolution of the community structure at the LD mats, RDA was used to identify trends between population structure and different types of co-registered data (Figure 4). The first two axes of the RDA plots explained a large percentage of the variance in the sample (96.1\%) (Figure 4) and reflected relationships discussed previously. For example, L. ochracea and Gallionellales are strongly separated along the first axis, a separation that is visible in their respective morphological structures, stalks and sheaths/particulates (Figure 2). The mat development patterns driven by hydrologic changes observed during the past 5 years at LD were apparent in the plot. Gallionellales abundance was located closer to the $\mathrm{Al}$ and $\mathrm{Ca}$ element vectors, present in clay weathering and groundwater seepage, compared with L. ochracea abundance. In contrast, L. ochracea was associated with greater rain fall than Gallionellales abundance. This analysis revealed several associations that we had not previously predicted. Species position in the biplot suggests that the transition between two groups of FeOB is reflected in the changes in elemental metal composition, with Gallionellales more often associated with $\mathrm{Ni}, \mathrm{Cu}$ and $\mathrm{Zn}$, and L. ochracea plotting with increased $\mathrm{Fe}$ and $\mathrm{Mn}$ concentrations. In addition, the RDA identified DOC quantity and size/aromaticity (spectral slope) as an important determinant of $L$. ochracea presence. A second RDA using the same suite of environmental variables (explanatory variables), but with the percentage of tagged pyrosequencing reads assigned to individual species (response variables), gave similar results as the FISH-based RDA (Figure 4).

\section{Discussion}

The work presented here shows clear evidence of an ecological succession in biogenic morphotypes of FeOB, from a stalk-dominated (Gallionella-related) iron mat ecosystem to one dominated by sheaths (indicative of $L$. ochracea). Molecular analysis shows a concomitant change in microbial population structure, from a predominance of Gallionellales to a greater $L$. ochracea prevalence. This succession was systematically documented for 2 years (2009 and 2010) and was observed each year from 2008 to 2012, indicating that this transition is a cyclic, stable feature of this iron-rich stream ecosystem. The unique iron-oxyhydroxide FeOB morphotypes made it possible to discover and document this succession, giving us the opportunity to resolve the environmental factors driving specific FeOB. Remarkably, the suite of environmental parameters that we measured explained $96 \%$ of the variance among the active $\mathrm{FeOB}$ (as detected by
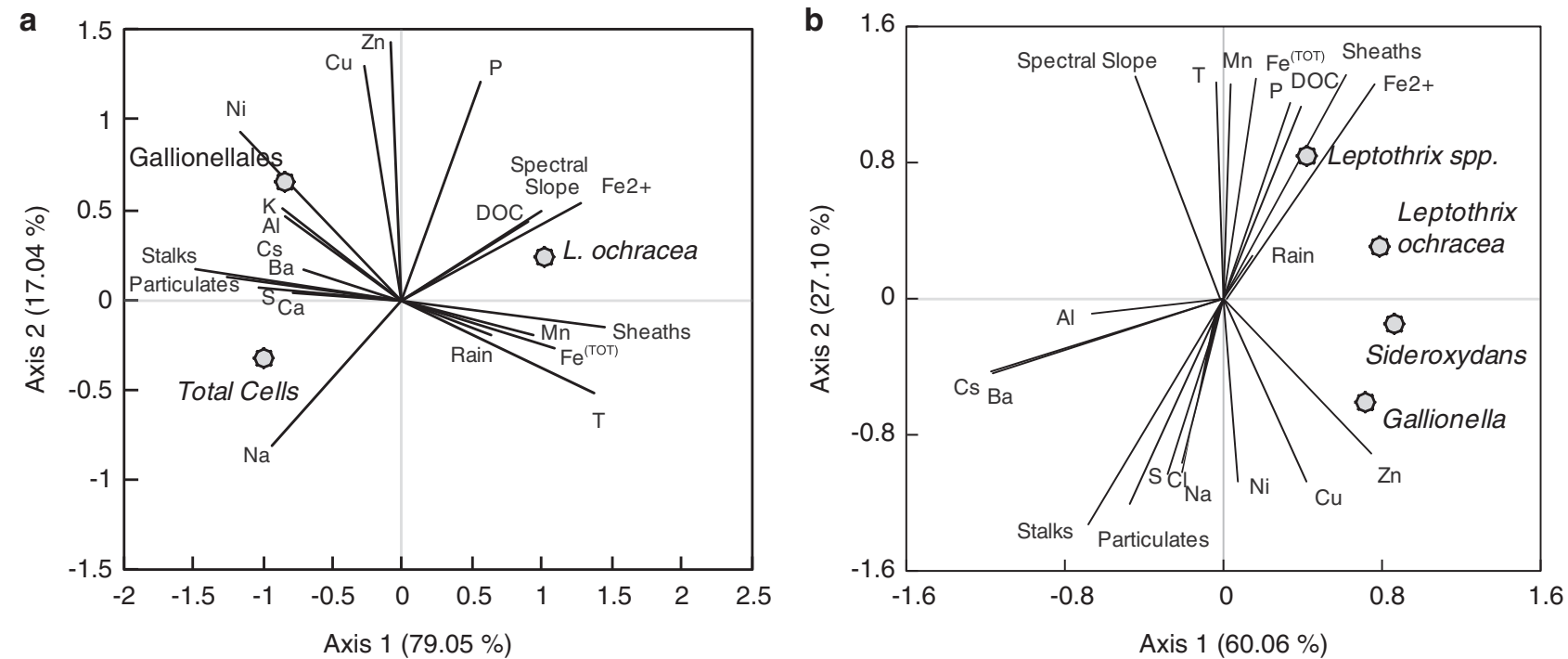

Figure 4. Biplot of RDA of the total cells, total L. ochracea cells and Gallionellales cells from direct counts using FISH probes (a) or sequence read abundance of specific taxa from pyrosequencing (b; dots, response variables) with structural Fe(III)-oxyhydroxide morphotypes, major elements, DOC, air temperature, water temperature and spectral slope of DOC (vectors, explanatory). 
FISH) within the surface layer of the LD iron mat ecosystem. This evidence supports the hypothesis for different niche preferences of the two dominant FeOB taxa (Gallionellales and L. ochracea), which can explain the ecological succession.

Two mat types prevailed at different positions in the stream, implying the potential role of spatial positioning and associated water flow on community composition. The stalk-forming Gallionellales occurred in condensed mats along seepages associated with the stream banks and weatheringassociated elements were greater, and L. ochracea developed in deeper, free-flowing stream sections and during greater rainfall. Other studies have observed L. ochracea growing in condensed mats with greater water flows (Emerson and Revsbech, 1994) and the presence of Gallionellales populations in slow-moving water channels (Harder, 1919; Rentz et al., 2007; Emerson unpublished observations). Hydrologic flow regimes are important determinants in chemical lability and mixing, and thus may help drive the differential spatial positioning of seasonal FeOB mats. For example, evidence suggests that Gallionellales are restricted to more oxygendepleted habitats, and L. ochracea has a wider tolerance of oxygen concentrations (Emerson and Revsbech, 1994; Rentz et al., 2007), although exceptions have been reported in L. ochracea mats with little $\mathrm{O}_{2}$ penetration (Emerson and Revsbech, 1994; Roden et al., 2012) and in technical water systems where stalk-forming Gallionella were present at high $\mathrm{O}_{2}$ concentrations (Søgaard et al., 2001; de Vet et al., 2011). Nonetheless, this hypothesis is consistent with oxygen profiles at LD: mats dominated by Gallionellales had steep oxygen gradients, and L. ochracea mats had more gradual oxygen gradients with overall oxygen concentrations that approached half-saturation.

It is plausible that synergistic effects of hydrodynamics, temperature, metal concentration and oxygen in LD create conditions favorable for a succession in FeOB dominance. Other studies on FeOB communities (both neutrophilic and acidophilic) have observed general changes in community structure that correspond with temperature, season or rain (Edwards et al., 1999; Hegler et al., 2012; Johnson et al., 2012). In particular, Gault et al. (2012) sampled a spring-fed iron mat in Chalk River, Ontario, once during each major season, and noted that the abundance of Gallionellales clones was greater in winter than in summer, consistent with the findings presented here. Interestingly, they also noted that sheaths were the dominant morphotype present throughout the year at this site, although conventional SSU rRNA clone libraries did not reveal the presence of $L$. ochracea. Seasonal temperature change may also be a proxy for other factors that are changing and altering population dynamics, rather than these changes being solely due to the specific temperature sensitivity of a population. Other variables including DOC concentration, size and aromaticity may also be an important determinant of population structure of specific FeOB taxa, particularly for L. ochracea populations (Figure 4). The cause of the seasonal shifts in the spectral slope ratio might be indicative of change in the dissolved matter origin, or due to different photochemical, biological or aggregation processes that are known to alter DOC MW and aromaticity (Floge and Wells, 2007; Helms et al., 2008). These findings as applied to the LD system could indicate the following: (1) Steep increases in spectral ratio associated with rain events bring in un-degraded organic material-compared with the ratios associated with older decomposed detrital matter of stagnant waters-as a fresh source of organic matter that provides a fresh carbon source (Chow et al., 2013). (2) The increase in rain-associated cloud cover causes a decrease in DOC photobleaching, the sunlight-induced conversion of larger, aromatic DOC molecules (larger spectral slope) into smaller MW molecules (smaller spectral slope), as demonstrated by Helms et al. (2008). Either possibility exposes a previously unexplored relationship between L. ochracea and organic carbon cycling.

Bogs, fens, tile drains and certain chalybeate springs are typically organic-rich environments and can be abundant with L. ochracea-rich mats (Harder, 1919). These waters, rich in complex decaying organic matter, retain $\mathrm{Fe}(\mathrm{II})$ and $\mathrm{Fe}(\mathrm{III})$ in solution despite circum-neutral $\mathrm{pH}$ or oxygenation (Emmenegger et al., 1998; Dhungana and Crumbliss 2005). L. ochracea seems to have an absolute requirement for high concentrations of iron (van Veen et al., 1978; Ghiorse, 1984; Emerson et al., 2010; Fleming, unpublished results), yet tolerates and proliferates in oxygen-rich environments, as demonstrated at LD. To exploit such niches, L. ochracea would require retardation of abiotic iron oxidation. By changing the iron reaction rates and retaining iron in solution, organic ligands (Liang et al., 1993; Rose and Waite, 2003) may promote L. ochracea growth. Alternatively the cooccurrence of L. ochracea and DOC may indicate that L. ochracea requires the DOC to grow heterotrophically or mixotrophically. Assimilation of carbon by L. ochracea has been debated for the past century (van Veen et al., 1978; Ghiorse, 1984; Winogradsky, 1888). The argument for heterotrophy relies on L. ochracea's close phylogenetic affiliation with heterotrophic relatives. Conversely, the arguments for autotrophy are based on its growth and ecological preferences, such as the production of small volumes of biomass with the need for high amounts of $\mathrm{Fe}$ (II) (a low-yielding energy source), and on its inability to grow on heterotrophic media (Emerson et al., 2010). Preliminary data suggest that L. ochracea contains genes for carbon fixation (Fleming et al., unpublished results).

The physiology and ecology of Gallionellales is better understood, in part because cultured representatives are available. These representatives 
include chemolithoautotrophs, which generate either stalks or particulate iron-oxyhydroxides and typically require low oxygen tensions (Emerson and Revsbech, 1994; Druschel et al., 2008; Li et al., 2010). The Gallionellales are phylogenetically diverse with several cultivated genera (reviewed in Emerson et al., 2010; Lüdecke et al., 2010; Krepski et al., 2011); Gallionellales SSU rRNA sequences are consistently abundant in clone libraries from iron mats (Haaijer et al., 2008; Duckworth et al., 2009; Wang et al., 2009; Bruun et al., 2010; Fleming et al., 2011; Gault et al., 2012; Kato et al., 2012; Roden et al., 2012). In April, LD iron mats began forming at localized seepage sites. Gallionellales stalks, cells and sequences were abundant, the oxygen gradients were steepest and the $\mathrm{pH}$ was greater. The $\mathrm{RDA}$ indicated that Gallionellales and stalk abundance negatively co-occurred with high concentrations of total iron, Mn, organic carbon complexity (spectral slope) and DOC. Then in May, when stalks and total Gallionellales cell counts decreased with time, the percentage of Gallionellales cells to total cells did not fall below $5 \%$ of the total population during the sampling period. In a second RDA with environmental variables and classified tagged pyrosequencing read abundance (Figure 4), Gallionella spp. coincided with stalks and particulates more often than did sheaths, and Sideroxydans spp. (not known to produce organized extracellular structures) did not coincide with any particular structure. These data indicate the presence of at least two Gallionellales populations in these mats, and that may change their physiology in response to seasonal signals. First, there is a stalk-forming Gallionellales population that prefers environments with tightly constrained redoxclines, environments in which $\mathrm{Fe}$ (II) is not stabilized by organic carbon and lower $\mathrm{pH}$ and thus $\mathrm{Fe}(\mathrm{II})$ does not persist in the more oxygenated zones above the mat. Second, there is a non-stalk-forming Gallionellales population that does not have a seasonal preference; possibly these cells adhere to the sheaths or stalks produced by other FeOB, to maintain an optimum position to access both iron and oxygen. A population succession among Gallionellales may explain why even in sheath-rich iron mats there are so many Gallionellales-SSU rRNA sequences present.

Several other taxa were consistently recovered at high percentages in the pyrotagged reads, including specific members of Bacteriodetes and presumptive methylotrophs. For example, Flavobacterium reads $(24.5 \%)$ were evident in the Gallionellalesdominated April sample after the stalk-sheath transition (late May) Methylobacter (5.8-20\% of total sequences) and unidentified environmental OTUs (6.5-20.5\%) were conspicuous in the L. ochracea-dominated samples. Sequences from these same taxa were recovered from multiple other neutrophilic iron mats, and there is growing evidence of the co-occurrence of OTUs related to Methylobacter or Flavobacterium with either
L. ochracea or Gallionellales (Bruun et al., 2010; Fru et al., 2012; Johnson et al., 2012; Kato et al., 2012). Recent work has more rigorously established linkages among taxa and functional genes related to methanotrophs or methylotrophs being present in iron-oxidizing ecosystems (Wang et al., 2012; Kato et al., 2013). It is not clear why these taxa regularly occur in high $\mathrm{Fe}(\mathrm{II})$ environments associated with FeOB. Although the capacity of some of these taxa to use $\mathrm{Fe}(\mathrm{II})$ as an energy source cannot be ruled out, it is more likely that redoxcline habitats where Fe(II) is abundant also contain methane. The interesting question will be to determine whether there are specific co-occurrences of these groups, which could suggest some type of mutualism, commensalism, competitive co-existence or niche overlap.

The present work reveals that it is likely a complex interplay of physical and chemical factors that results in a marked ecological succession between the Gallionellales and L. ochracea. Further work is required to determine which factor or factors, for example quantity and quality of DOC, might provide a tipping point that drives dominance of one group within the microbial mat community. Because iron mats are easily recognized by the eye, and the characteristic stalks or sheaths are easily recognized by light microscopy, FeOB provide a useful model for studying the role of physiological adaptations and behavioral strategies in ecological succession and competition.

\section{Conflict of Interest}

The authors declare no conflict of interest.

\section{Acknowledgements}

We would like to thank Steve Bryer and David Gaecklin for regular access to the LD field site, Carly Hallowell for processing the ICP-OES data, Debbie Powell for SEM analyses, and Prof. Mary Jane Perry for support and discussion. We are also grateful to Dr Joyce McBeth, Nicole Brisson, Dr Beth Orcutt, Dr Jarrod J. Scott and Jaime Blair for help with data collection, data processing and comments on the manuscript. This work was funded by support from the National Science Foundation (IOS-0951077). IC would like to acknowledge the support from NASA (NNX13AC42G).

\section{Author contributions}

EJF-designing, analysis, writing; IC-analysis, instrumentation, writing; CSC-analysis, instrumentation, writing; DWK—analysis, instrumentation; DE—designing, analysis, writing.

\section{References}

Bruun A-M, Finster K, Gunnlaugsson H, Nørnberg P, Friedrich MW. (2010). A comprehensive investigation of iron cycling in a freshwater seep including microscopy, cultivation and molecular community analysis. Geomicrobiol J 27: 15-34. 
Chan CS, Fakra SC, Emerson D, Fleming EJ, Edwards KJ. (2011). Lithotrophic iron-oxidizing bacteria produce organic stalks to control mineral growth: implications for biosignature formation. ISME $J \mathbf{5}$ : 717-727.

Chow AT, Dai J, Conner WH, Hitchcock DR, Wang J-J. (2013). Dissolved organic matter and nutrient dynamics of a coastal freshwater forested wetland in Winyah Bay, South Carolina. Biogeochem 112: $571-587$.

de Vet WWJM, Dinkla IJT, Rietveld LC, van Loosdrecht MCM. (2011). Biological iron oxidation by Gallionella spp. in drinking water production under fully aerated conditions. Water Res 45: 5389-5398.

Dhungana S, Crumbliss A. (2005). Coordination chemistry and redox processes in siderophore-mediated iron transport. Geomicrobiol J 22: 87-98.

Dowd SE, Callaway TR, Wolcott RD, Sun Y, McKeehan T, Hagevoort RG et al. (2008). Evaluation of the bacterial diversity in the feces of cattle using 16S rDNA bacterial tag-encoded FLX amplicon pyrosequencing (bTEFAP). BMC Microbiol 8: 125.

Druschel G, Emerson D, Sutka R, Suchecki P, Luther GW III. (2008). Low-oxygen and chemical kinetic constraints on the geochemical niche of neutrophilic iron(II) oxidizing microorganisms. Geochim Cosmochim Acta 72: 3358-3370.

Duckworth OW, Holmstrom S, Pena J, Sposito G. (2009). Biogeochemistry of iron oxidation in a circumneutral freshwater habitat. Chem Geol 260: 149-158.

Edwards KJ, Gihring TM, Banfield JF. (1999). Seasonal variations in microbial populations and environmental conditions in an extreme acid mine drainage environment. Appl Environ Microbiol 65: 3627-3632.

Emerson D, Fleming EJ, McBeth JM. (2010). Iron-oxidizing bacteria: an environmental and genomic perspective. Annu Rev Microbiol 64: 561-583.

Emerson D, Weiss J. (2004). Bacterial iron oxidation in circumneutral freshwater habitats: findings from the field and the laboratory. Geomicrobiol J 21: 405-414.

Emerson D, Moyer CL. (1997). Isolation and characterization of novel iron-oxidizing bacteria that grow at circumneutral pH. Appl Environ Microbiol 63: 4784-4792.

Emerson D, Moyer CL. (2002). Neutrophilic Fe-oxidizing bacteria are abundant at the Loihi Seamount hydrothermal vents and play a major role in $\mathrm{Fe}$ oxide deposition. Appl Environ Microbiol 68: 3085-3093.

Emerson D, Revsbech N. (1994). Investigation of an iron-oxidizing microbial mat community located near Aarhus, Denmark: field studies. Appl Environ Microbiol 60: 4022-4031.

Emmenegger L, King D, Sigg L, Sulzberger. B. (1998). Oxidation kinetics of Fe (II) in a eutrophic Swiss lake. Environ Sci Technol 32: 2990-2996.

Fleming EJ, Langdon AE, Martinez-Garcia M, Stepanauskas R, Poulton NJ, Masland EDP et al. (2011). What's new is old: resolving the identity of Leptothrix ochracea using single cell genomics, pyrosequencing and FISH. PLoS One 6: e17769.

Floge SA, Wells ML. (2007). Variation in colloidal chromophoric dissolved organic matter in the Damariscotta Estuary, Maine. Limnol and Oceanogr 52: 32-45.

Fru EC, Piccinelli P, Fortin D. (2012). Insights into the global microbial community structure associated with iron oxyhydroxide minerals deposited in the aerobic biogeosphere. Geomicrobiol J 29: 587-610.

Fuchs BM, Pernthaler J, Amann R. (2007). Single cell identification by fluorescence in situ hybridization Beveridge TJ, Reddy CA, Breznak JA, Marzluf G, Schmidt TM, Snyder LR (eds). Methods Gen Mol Microbiol. ASM press: Washington DC, pp 886-896.

Gault AG, Langley S, Ibrahim A, Renaud R, Takahashi Y, Boothman C et al. (2012). Seasonal changes in mineralogy, geochemistry and microbial community of bacteriogenic iron oxides (BIOS) deposited in a circumneutral wetland. Geomicrobiol $J$ 29: 161-172.

Ghiorse W. (1984). Biology of iron- and manganese-depositing bacteria. Annu Rev Microbiol 38: $515-550$.

Haaijer SCM, Harhangi HR, Meijerink BB, Strous M, Pol A, Smolders AJP et al. (2008). Bacteria associated with iron seeps in a sulfur-rich, neutral $\mathrm{pH}$, freshwater ecosystem. ISME J 2: 1231-1242.

Harder E. (1919). Iron-depositing bacteria and their geologic relations. Department of the Interior, Government Printing Office: Washington DC.

Hegler F, Lösekann-Behrens T, Hanselmann K, Behrens S, Kappler A. (2012). Influence of seasonal and geochemical changes on the geomicrobiology of an iron carbonate mineral water spring. Appl Environ Microbiol 78: 7185-7196.

Helms JR, Stubbins A, Ritchie JD, Minor EC, Kieber DJ, Mopper K. (2008). Absorption spectral slopes and slope ratios as indicators of molecular weight, source, and photobleaching of chromophoric dissolved organic matter. Limnol and Oceanogr 53: 955-969.

Johnson KW, Carmichael MJ, McDonald W, Rose N, Pitchford J, Windelspecht $\mathrm{M}$ et al. (2012). Increased abundance of Gallionella spp., Leptothrix spp. and total bacteria in response to enhanced $\mathrm{Mn}$ and $\mathrm{Fe}$ concentrations in a disturbed southern Appalachian high elevation wetland. Geomicrobiol $J$ 29: 124-138.

Kato S, Kikuchi S, Kashiwabara T, Takahashi Y, Suzuki K, Itoh T et al. (2012). Prokaryotic abundance and community composition in a freshwater iron-rich microbial mat at circumneutral pH. Geomicrobiol J 29: 896-905.

Kato S, Chan C, Itoh T, Ohkuma M. (2013). Functional gene analysis of freshwater iron-rich flocs at circumneutral $\mathrm{pH}$ and isolation of a stalk-forming microaerophilic iron-oxidizing bacterium. Appl Environ Microbiol 79: 5283-5290. (Early Release).

Kent AD, Yannarell AC, Rusak JA, Triplett EW, McMahon KD. (2007). Synchrony in aquatic microbial community dynamics. ISME J 1: 38-47.

Katsoyiannis IA, Zouboulis AI. (2006). Use of iron- and manganese-oxidizing bacteria for the combined removal of iron, manganese and arsenic from contaminated groundwater. Water Qual Res J Can 41: 117-129.

Krepski ST, Hanson TE, Chan CS. (2011). Isolation and characterization of a novel biomineral stalk-forming iron-oxidizing bacterium from a circumneutral groundwater seep. Environ Microbiol 14: 1671-1680.

Liang L, McNabb JA, Paulk JM, Gu B, McCarthy JF. (1993). Kinetics of $\mathrm{Fe}(\mathrm{II})$ oxygenation at low partial pressure of oxygen in the presence of natural organic matter. Environ Sci Tech 27: 1864-1870.

Li D, Li Z, Yu J, Cao N, Liu R, Yang M. (2010). Characterization of bacterial community structure in a drinking water 
distribution system during an occurrence of red water. Appl Environ Microbiol 76: 7171-7180.

Lüdecke C, Reiche M, Eusterhues K, Nietzsche S, Küsel K. (2010). Acid-tolerant microaerophilic Fe(II)-oxidizing bacteria promote Fe(III)-accumulation in a fen. Environ Microbiol 12: 2814-2825.

Ludwig W, Strunk O, Westram R, Richter L, Meier H, Yadhukumar et al. (2004). ARB: a software environment for sequence data. Nucleic Acids Res 32: 1363-1371.

McBeth JM, Fleming EJ, Emerson D. (2013). The transition from freshwater to marine iron-oxidizing bacterial lineages along a salinity gradient on the Sheepscot River, Maine USA. Environ Microbiol Rep 5: 453-463.

Pruesse E, Quast C, Knittel K, Fuchs BM, Ludwig W, Peplies J et al. (2007). SILVA a comprehensive online resource for quality checked and aligned ribosomal RNA sequence data compatible with ARB. Nucleic Acids Res 35: 7188-7196.

R Core Team (2012). R: A Language and Environment for Statistical Computing. R Foundation for Statistical Computing: Vienna, Austria, ISBN 3-900051-07ohttp://www.R-project.org/.

Ramette A. (2007). Multivariate analyses in microbial ecology. FEMS Microbiol Ecol 62: 142-160.

Rasband W. (2004). ImageJ: image processing and analysis in java. Book Public Domain, http://rsbweb.nih.gov/ij/.

Rentz JA, Kraiya C, Luther GW III, Emerson D. (2007). Control of ferrous iron oxidation within circumneutral microbial iron mats by cellular activity and autocatalysis. Environ Sci Technol 41: 6084-6089.

Roden EE, McBeth JM, Blöthe M, Percak-Dennett EM, Fleming EJ, Holyoke RR et al. (2012). The microbial ferrous wheel in a neutral $\mathrm{pH}$ groundwater seep. Front Microbiol 3: 172.
Rose A, Waite T. (2003). Effect of dissolved natural organic matter on the kinetics of ferrous iron oxygenation in seawater. Environ Sci Technol 37: 4877-4886.

Schloss PD, Gevers D, Westcott SL. (2011). Reducing the effects of PCR amplification and sequencing artifacts on 16S rRNA-based studies. PLoS One 6: e27310.

Søgaard EG, Aruna R, Abraham-Peskir J, Koch CB. (2001). Conditions for biological precipitation of iron by Gallionella ferruginea in a slightly polluted ground water. Appl Geochem 16: 1129-1137.

Stookey LL. (1970). Ferrozine-a new spectrophotometric reagent for iron. Anal Chem 42: 779-781.

Sugimura Y, Suzuki Y. (1988). A high temperature catalytic oxidation method for the determination of non-volatile dissolved organic carbon in seawater by direct injection of a liquid sample. Mar Chem 24: 105-131. (EPA Method 415.1).

van Veen W, Mulder E, Deinema M. (1978). The SphaerotilusLeptothrix group of bacteria. Microbiol Rev 42: 329-356.

Wang J, Muyzer G, Bodelier PLE, Laanbroek HJ. (2009). Diversity of iron oxidizers in wetland soils revealed by novel 16S rRNA primers targeting Gallionella-related bacteria. ISME J 3: 715-725.

Wang J, Krause S, Muyzer G, Meima-Franke M, Laanbroek HJ, Bodelier PLE. (2012). Spatial patterns of iron- and methane-oxidizing bacterial communities in an irregularly flooded, riparian wetland. Front Microbiol 3: 1-13.

Weiss JV, Rentz JA, Plaia T, Neubauer SC, Merrill-Floyd M, Lilburn T et al. (2007). Characterization of neutrophilic $\mathrm{Fe}(\mathrm{II})$-oxidizing bacteria isolated from the rhizosphere of wetland plants and description of Ferritrophicum radicicola gen. nov. sp. nov., and Sideroxydans paludicola sp. nov. Geomicrobiol J 24: 559-570.

Winogradsky S. (1888). Ueber Eisenbacterien. Botanishe Zeitung 46: 261-271.

Supplementary Information accompanies this paper on The ISME Journal website (http://www.nature.com/ismej) 